\title{
Optimalisasi Heat Treatment pada Proses Daur Ulang Pegas Daun Mobil untuk Pembuatan Pisau Sembelih Rumah Pemotongan Hewan
}

\author{
Abdul Choliq ${ }^{1, a)}$ dan DN. Adnyana ${ }^{1, b)}$ \\ ${ }_{1}^{1}$ Institut Sains Dan Teknologi Nasional Jakarta

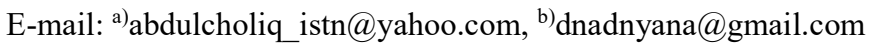 \\ Masuk:27 Februari 2018 Direvisi : 26 Maret 2018 Disetujui : 5 Juni 2018
}

\begin{abstract}
Abstrak: Pisau sembelih merupakan alat penting dalam kegiatan pemotongan ternak besar di rumah pemotongan hewan untuk pemenuhan konsumsi daging bagi masyarakat, selain itu juga peranti pemotongan ternak untuk kepentingan keluarga, upacara adat, dan peribadatan, seperti pada saat Idul Adha. Ketersediaan pisau sembelih dengan kualitas bagus masih menjadi persoalan tersendiri di masyarakat, karena harga pisau buatan pabrik dirasa masih cukup mahal oleh sebagian orang. Telah banyak yang mencoba untuk membuat pisau alternative dengan memanfaatkan berbagai limbah baja, namun hasilnya belum cukup memuaskan. Kualitas pisau sembelih hewan sangat dipengaruhi oleh tingkat kekerasan dan ketangguhan material pisau yang optimal. Sifat tersebut sangat dipengaruhi oleh komposisi kimia dan struktur mikro material. Untuk mencapai struktur mikro yang dapat memberikan kombinasi sifat keras dan tangguh pisau, maka diperlukan perlakuan panas (heat treatment) yang memadai. Dalam penelitian ini telah dilakukan daur ulang limbah pegas daun mobil yang memiliki kekerasan 419HV dan 460HV serta struktur mikro matrik martensit temper untuk dibuat bilah pisau melalui proses tempa tangan dan perlakuan panas menggunakan media pendingin yang berbeda, yaitu air, oli mesin bekas, dan batang pohon pisang. Pengujian yang dilakukan meliputi uji komposisi kimia, uji metalografi dan uji kekerasan. Hasil pengujian menunjukkan bahwa kekerasan pisau percobaan A pada daerah mata pisau mencapai $730 \mathrm{HV}$ dengan struktur mikro martensit dan karbida krom, dan pada daerah tumpul kekerasannya turun pada level $313 \mathrm{HV}$ dengan struktur martensit dan austenit sisa. Sementara itu pisau percobaan B yang dikeraskan secara menyeluruh mencapai kekerasan $627 \mathrm{HV}$ dan struktur mikro martensit dengan karbida krom halus menyebar rata. Hasil percobaan pembuatan pisau yang diperoleh mendekati sifat mekanik pisau impor X yang memiliki struktur mikro matrik martensit temper dengan karbida dan level kekerasannya $640 \mathrm{HV}$. Disimpulkan bahwa kedua pegas cukup bagus untuk material alternatif untuk bilah pisau sembelih hewan yang dimanfaatkan di rumah pemotongan hewan.
\end{abstract}

Keywords: Pisau sembelih hewan, rumah pemotongan hewan, pegas daun mobil, tempa, perlakuan panas.

\begin{abstract}
Abstrak: The slaughter knife is an important tool in the slaughtering activities of large livestock in abattoir to meet the needs of meat consumption for the public. It is also for butchering activities for the family events, traditional ceremony and worship such as Eid-al Adha. The availability of the slaughter knife with good quality still be a problem in the public, because the price of knifes are considered expensive by some people. Many people tried to make the alternative knifes from various waste of steel, however the results are not quite satisfying. The quality of slaughter knifes are strongly influenced by the optimum hardness level and toughness of the knife. The properties are influenced by the chemical composition of material and micro structure. To achieve a micro structure that combines of hard and tough knife, it is necessary to do heat treatment. In this research, recycling of the waste of car leaf spring with hardness level $419 H \mathrm{~V}$ and $460 \mathrm{HV}$ and microstructure matrix martensit tempered has been done to make slaughter knives through hand forging and heat treatment processing using different cooling media, namely water, used engine oil, and banana tree trunks. The testing was done through chemical composition testing, metallography testing, and hardness testing. The result showed that the hardness level of trial knife A at sharp area could reach until $730 H V$ with microstructure martensite and chrom carbide. And at blunt area, the hardness has dropped to level $313 \mathrm{HV}$. In the meantime, the trial knife B which has hardened thoroughly could reach until level $627 H V$ and the martensit microstructure with fine chromium carbide spreads evenly. Thus the obtained results of trial knife resembled to the characteristic of the imported knife $X$, which has the microstructure matrix martensite temper and speroidized carbida with the hardness level up to $614 \mathrm{HV}$. In conclusion, both springs are good enough as alternative materials for slaughter knifes that can be used in an abattoir.
\end{abstract}

Kata kunci: $\mathrm{Fe}-50 \% \mathrm{Al}$, coating, struktur, kekerasan, mechanical alloying 
28 | Abdul Choliq, dkk., Optimalisasi Heat Treatment pada Proses Daur Ulang Pegas ....,

\section{PENDAHULUAN}

Penyembelihan hewan ternak untuk kebutuhan kosumsi daging bagi masyarakat Indonesia terus meningkat seiring jumlah pertumbuhan penduduk serta meningkatnya pendapatan perkapita masyarakat. Data Badan Pusat Statistik bulan Juni 2018 (Tabel 1) mencatat jumlah pemotongan ternak besar yang dilaporkan pada beberapa tahun terakhir terus meningkat [1]. Tabel 2 adalah data Kementrian Pertanian 2016-2018 tentang kebutuhan hewan untuk qurban pada Idul Adha setiap tahun juga meningkat [7]. Seiring peningkatan kegiatan pemotongan hewan, maka pertumbuhan rumah potong hewan (RPH) dan tempat pemotongan hewan (TPH) di Indonesia juga bertambah. Data Direktori Perusahaan Pertanian tahun 2018 (Tabel 3) mencatat total RPH dan TPH Indonesia sebanyak 1.201 tempat [6].

Tabel 1. Jumlah hewan dipotong di RPH dan luar RPH yang dilaporkan tahun 2013-2017

\begin{tabular}{llrrrrr}
\hline \multirow{2}{*}{ No } & \multirow{2}{*}{$\begin{array}{c}\text { Jenis Ternak-Ternak } \\
\text { Besar }\end{array}$} & \multicolumn{5}{c}{ Tahun } \\
\cline { 3 - 7 } & & \multicolumn{1}{c}{$\mathbf{2 0 1 3}$} & $\mathbf{2 0 1 4}$ & $\mathbf{2 0 1 5}$ & $\mathbf{2 0 1 6}$ & $\mathbf{2 0 1 7}$ \\
\hline 1 & Sapi & 1.326 .395 & 1.088 .140 & 1.207 .170 & 1.163 .459 & 1.114 .748 \\
2 & Kerbau & 41.974 & 36.145 & 34.96 & 37.797 & 32.909 \\
3 & Kuda & 3.368 & 3.358 & 3.292 & 3.162 & 3.094 \\
4 & Kambing & 274.943 & 211.59 & 212.589 & 186.628 & 193.649 \\
5 & Domba & 142.736 & 93.578 & 99.987 & 93.342 & 17.704 \\
6 & Babi & 538.101 & 458.153 & 474.277 & 546.65 & 518.602 \\
\hline
\end{tabular}

Sumber: Badan Pusat Statistik, 2018

Tabel 2. Kebutuhan hewan qurban 2016-2018

\begin{tabular}{|c|c|c|c|c|}
\hline \multirow{2}{*}{ No } & \multirow{2}{*}{ Jenis Hewan } & \multicolumn{3}{|c|}{ Tahun } \\
\hline & & 2016 & 2017 & 2018 \\
\hline 1. & Sapi & 279.221 & 440.323 & 462.399 \\
\hline 2. & Kerbau & 7.535 & 9.851 & 10.344 \\
\hline 3. & Kambing & 650.583 & 755.288 & 793.052 \\
\hline 4. & Domba & 82.438 & 227.479 & 238.853 \\
\hline Total & & 1.019 .777 & 1.432 .940 & 1.504 .588 \\
\hline
\end{tabular}

Tabel 3. Jumlah RPH dan TPH di Indonesia tahun 2018

\begin{tabular}{|c|c|c|c|}
\hline \multirow{2}{*}{ No. } & \multirow{2}{*}{ Pulau } & \multicolumn{2}{|c|}{ RPH dan TPH } \\
\hline & & Jumlah & $\%$ \\
\hline 1 & Sumatera & 227 & 18,90 \\
\hline 2 & Jawa & 527 & 43,88 \\
\hline 3 & Bali dan Nusa Tenggara & 136 & 11,32 \\
\hline 4 & Kalimantan & 83 & 6,91 \\
\hline 5 & Sulawesi & 178 & 14,82 \\
\hline 6 & Maluku dan Papua & 50 & 4,16 \\
\hline Jumlah & Indonesia & 1201 & 100 \\
\hline
\end{tabular}

Sumber: Katalog Badan Pusat Statistik No. 1305016, 2018

Meningkatnya kegiatan penyembelihan hewan menjadi sinyal bahwa prospek pengembangan industri pisau sembelih di Indonesia masih cukup terbuka. Saat ini tersedia banyak pisau sembelih impor yang memiliki performa bagus, namun karena berbagai persoalan sosial dan ekonomi masyarakat, maka tidak banyak yang mampu memiliki pisau-pisau tersebut. Penggunaan pisau-pisau sembelih buatan lokal masih dominan digunakan dalam kegiatan pemotongan hewan. Eksistensi pisau sembelih buatan lokal masih memiliki pangsa pasar tersendiri di masyarakat [15]. Pisau impor dibuat di pabrik manufaktur secara masal dengan proses tempa die forging untuk memperoleh bentuk dan pemadatan dilanjutkan dengan heat treatment. Pisau lokal dibuat dengan proses tempa bebas, yaitu secara manual melalui beberapa tahap penggarapan $[5,11]$ dan heat treatment. 
Material alternative untuk bilah pisau sembelih banyak diambil dari limbah baja, seperti pegas daun mobil, bearing, sling, cakram motor, dll. Kekerasan bilah pisau sembelih umumnya mencapai 600 HV [12]. Sifat tersebut sangat dipengaruhi oleh kualitas material yang meliputi komposisi kimia dan struktur mikro material $[2,9]$, serta metode pembuatan yang meliputi proses tempa dan penyepuhan [2,3]. Media quenching semisal air, oli, dan batang pisang [14] sangat mempengaruhi hasil perlakuan panas.

Penelitian ini bertujuan untuk mengetahui alasan pemilihan pegas daun mobil sebagai material alternative untuk bilah pisau sembelih. Selain itu untuk menyimpulkan metode tempa dan heat treatment yang sesuai dalam pembuatan bilah pisau agar memperoleh karakter mendekati pisau sembelih impor. Pemanfaatan pegas untuk bahan pisau termasuk upaya mendaur ulang limbah yang kurang bernilai menjadi produk yang lebih bernilai, sehingga diharapkan mengangkat ekonomi masyarakat pengrajin perkakas besi, sekaligus usaha menggali dan mengangkat potensi lokal agar lebih dikenal, menjawab kebutuhan masyarakat, serta memiliki daya saing di tengah serbuan produk-produk asing.

\section{METODOLOGI}

Material yang diteliti terdiri dari pegas daun mobil A (Gambar 1a), B (Gambar 1b) dan pisau impor X (Gambar 1c) sebagai acuan pembuatan pisau percobaan. Pegas dijadikan beberapa sampel hardening dengan dimensi p x $1 \times$ t $(120 \times 50 \times 12 \mathrm{~mm})$ dan 2 material pisau percobaan dengan dimensi awal p x $1 \times \mathrm{t}(200 \times 50 \times$ $12 \mathrm{~mm})$.

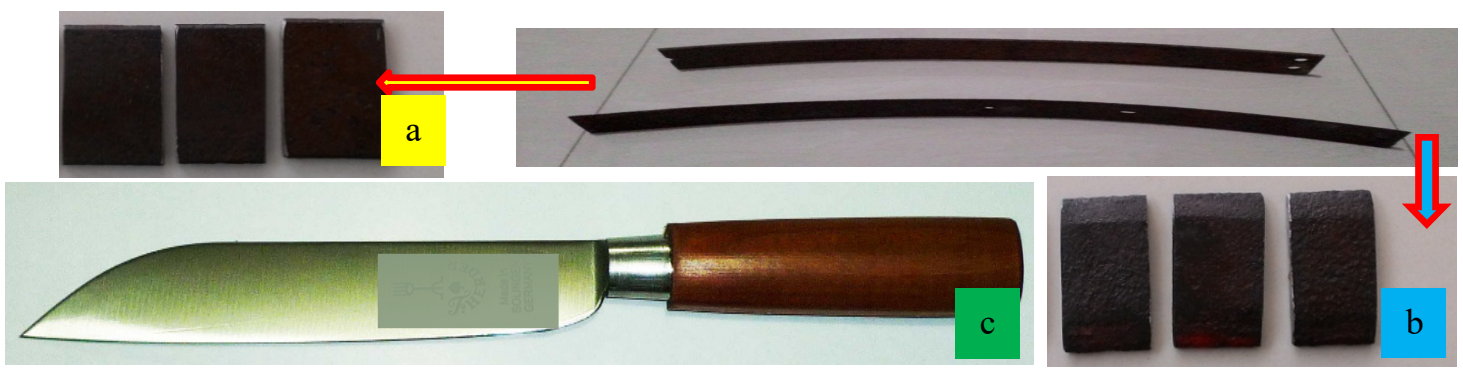

Gambar 1. Makro material penelitian.

Alat pemanas berupa tungku tradisional berbahan bakar arang kayu yang bagian bawahnya dihubungkan dengan penghembus udara berupa blower $35 \mathrm{~W}$ dengan pipa outlet 2 ". Pengukuran temperatur dengan infrared thermometer berkapasitas ukur $-32^{\circ} \mathrm{C}-900^{\circ} \mathrm{C}$.
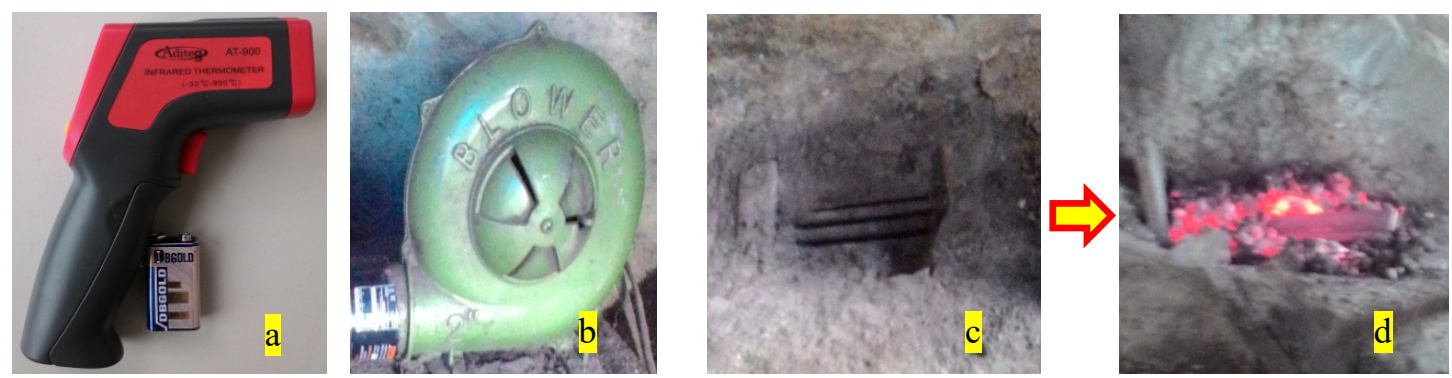

Gambar 2. Infrared thermometer (a), blower (b), tungku arang tradisional kondisi mati (c), dan tungku arang kondisi membara tanpa hembusan blower (d)

Berikut adalah diagram alir dalam pelaksanaan penelitian terhadap pegas daun mobil A dan B serta salah satu pisau impor dengan merk dagang $\mathrm{X}$ yang banyak digunakan dalam operasi pemotongan hewan di Rumah Pemotongan Hewan (RPH). 


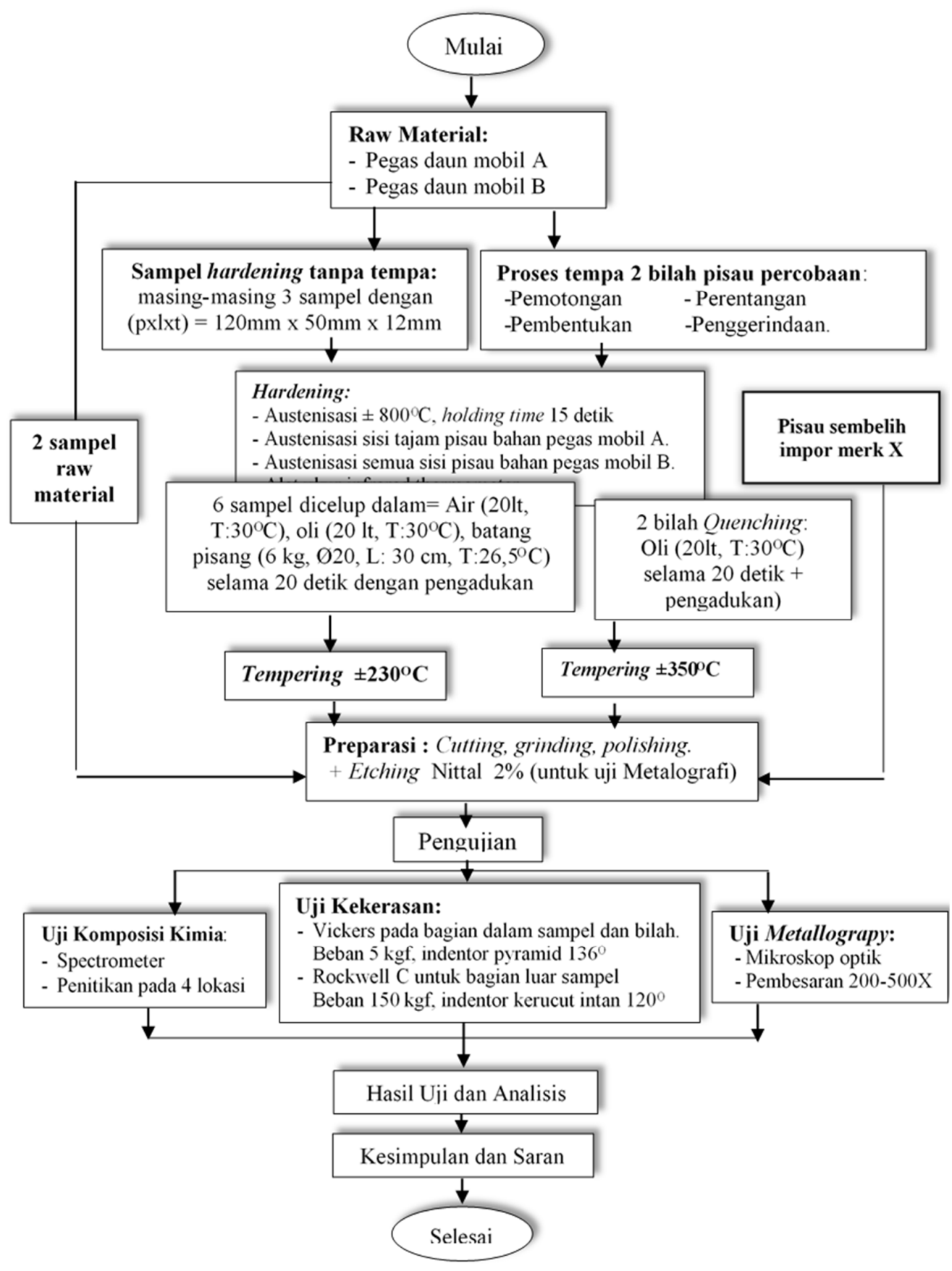

Gambar 3. Diagram alir dalam pelaksanaan penelitian

\section{HASIL DAN PEMBAHASAN}

\section{Komposisi Kimia}

Pisau impor X, pegas mobil A dan B memiliki komposisi kimia berbeda (Tabel 4). Ketiganya termasuk baja karbon medium dengan paduan $<8 \%$. Pisau impor $\mathrm{X}$ dengan paduan $\mathrm{Cr}$ 0,3\%, dan Ni 0,8\% memiliki sifat mampu bentuk dan mampu keras yang baik [16]. Komposisi material pisau X mendekati AISI 1060 [4]. Pegas A memiliki kadar Si dan Mn cukup tinggi yaitu 1,81\%. Kondisi ini akan menjadikannya memiliki yield point tinggi, namun 
apabila ditempa akan membutuhkan tenaga lebih karena keras [16]. Material yang mendekati pegas A adalah AISI 9260 [4]. Pegas mobil B berkadar Cr dan Ni tinggi akan menjadikannya keras. Selain itu Cr, Al dan $\mathrm{Cu}$ yang lebih akan menjadikan pegas B lebih tahan karat [16]. Material dengan komposisi yang mendekati pegas B adalah AISI 5160 [4]

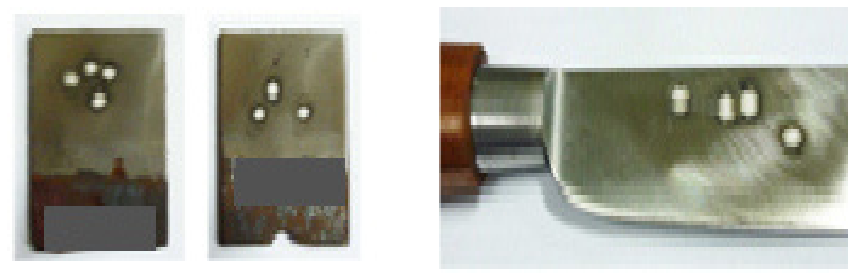

Gambar 4. Bekas penitikan uji komposisi kimia

Tabel 4. Komposisi material dalam \%

\begin{tabular}{cccccccccccccc}
\hline No & Sampel & $\mathbf{C}$ & Si & Mn & Cr & Ni & Mo & Cu & Al & S & P & Co & Sisa \\
\hline 1. & Pisau X & 0,67 & 0,20 & 0,80 & 0,32 & 0,08 & 0,017 & 0,151 & 0,009 & 0,02 & 0,04 & 0,03 & 97,5 \\
2. & Pegas A & 0,67 & 1,81 & 0,84 & 0,14 & 0,06 & 0,013 & 0,079 & 0,018 & 0,02 & 0,02 & 0,03 & 96,2 \\
3. & Pegas B & 0,58 & 0,26 & 0,77 & 0,82 & 0,09 & 0,042 & 0,141 & 0,032 & 0,01 & 0,03 & 0,03 & 97,1 \\
\hline
\end{tabular}

\section{Hasil Pengujian Struktur Mikro dan Analisis} $\mathrm{B}(\mathrm{c})$.

Berikut adalah gambar pengambilan specimen dari pisau impor $\mathrm{X}(\mathrm{a})$, sampel pegas $\mathrm{A}(\mathrm{b})$ dan sampel pegas
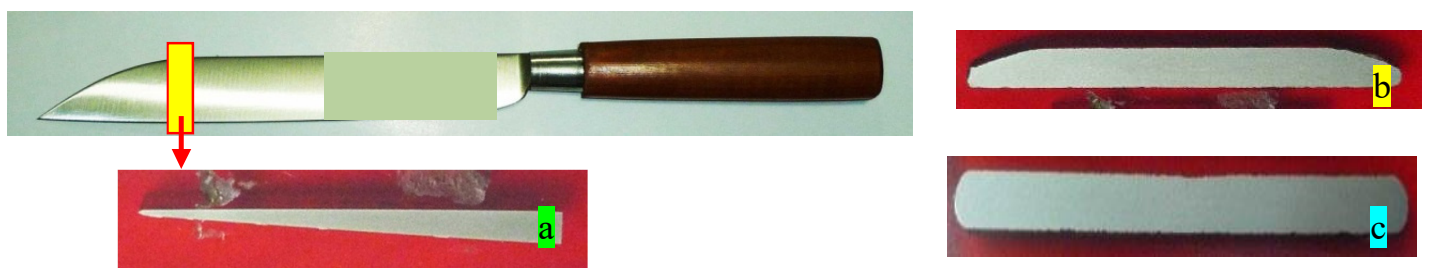

Gambar 5. Spesimen untuk uji struktur mikro

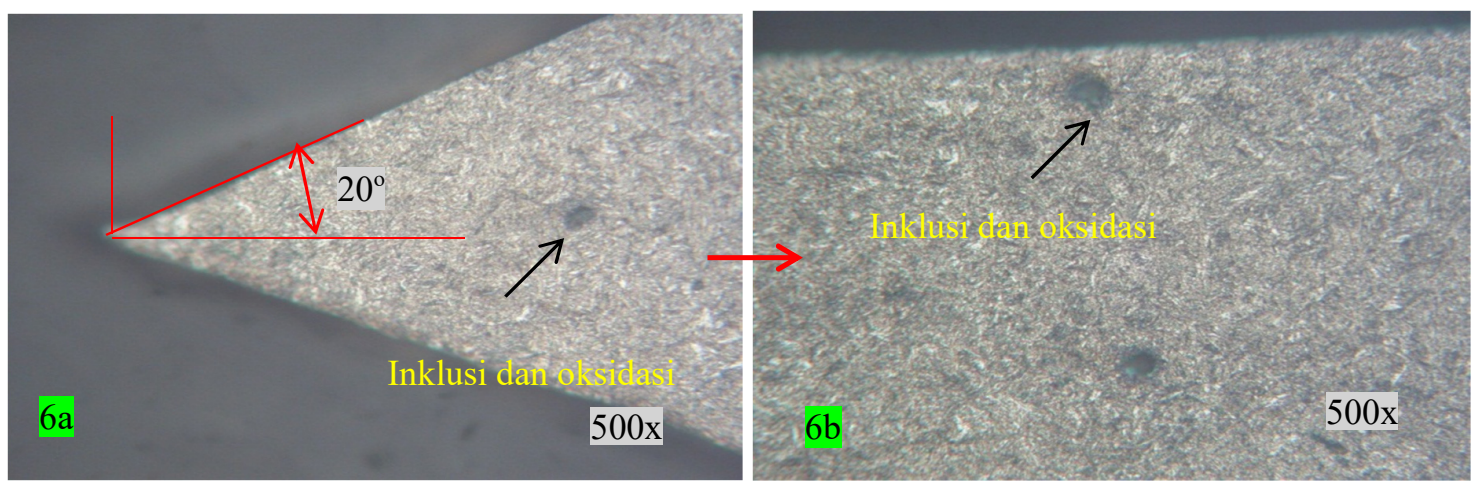

Gambar 6. Foto Struktur mikro pisau sembelih impor merk X

Pada ujung mata pisau impor X (Gambar 6a) membentuk sudut $20^{\circ}$, struktur mikro dari bagian tajam ke punggung pisau (Gambar 6b) berupa matrik martensit temper dengan butir karbida halus menyebar rata serta, tampak bintik berupa inklusi (oxide inclusion). 
32 | Abdul Choliq, dkk., Optimalisasi Heat Treatment pada Proses Daur Ulang Pegas ....,
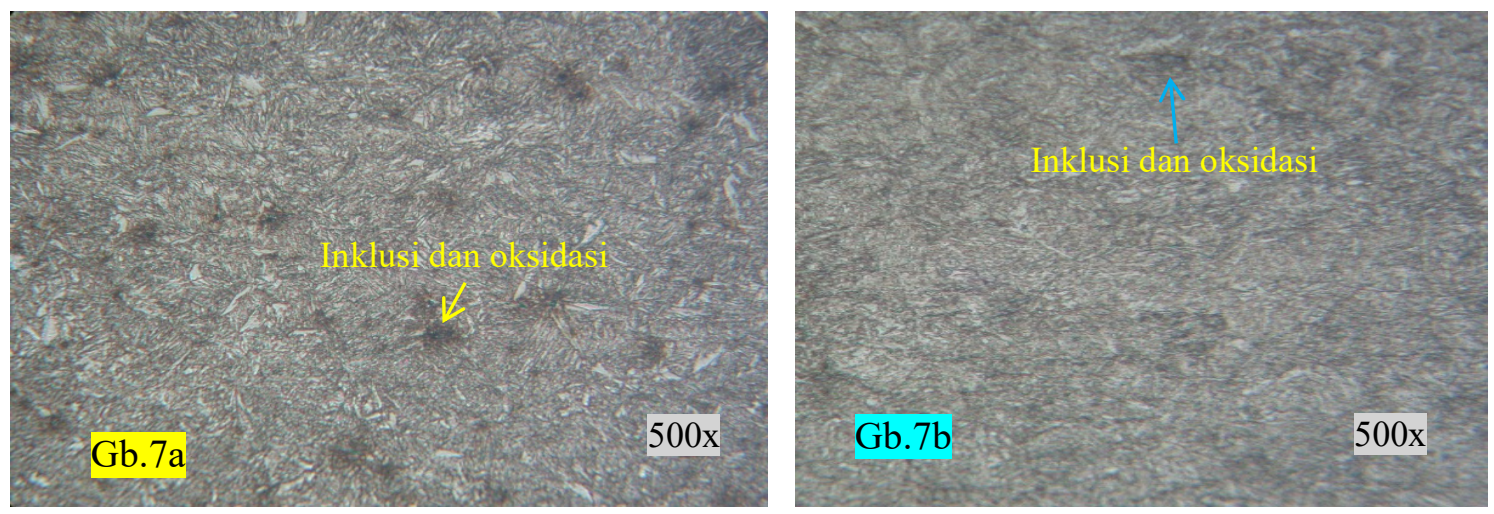

Gambar 7. Struktur mikro raw material pegas

Struktur mikro raw material pegas A (Gambar 7a) dan pegas daun mobil B (Gambar 7b) berupa matrik martensit temper dengan butir karbida halus (putih) menyebar rata. Pada kedua sampel tampak banyak bintik berupa inklusi (oxide inclusion) dalam ukuran dan jumlah berbeda.
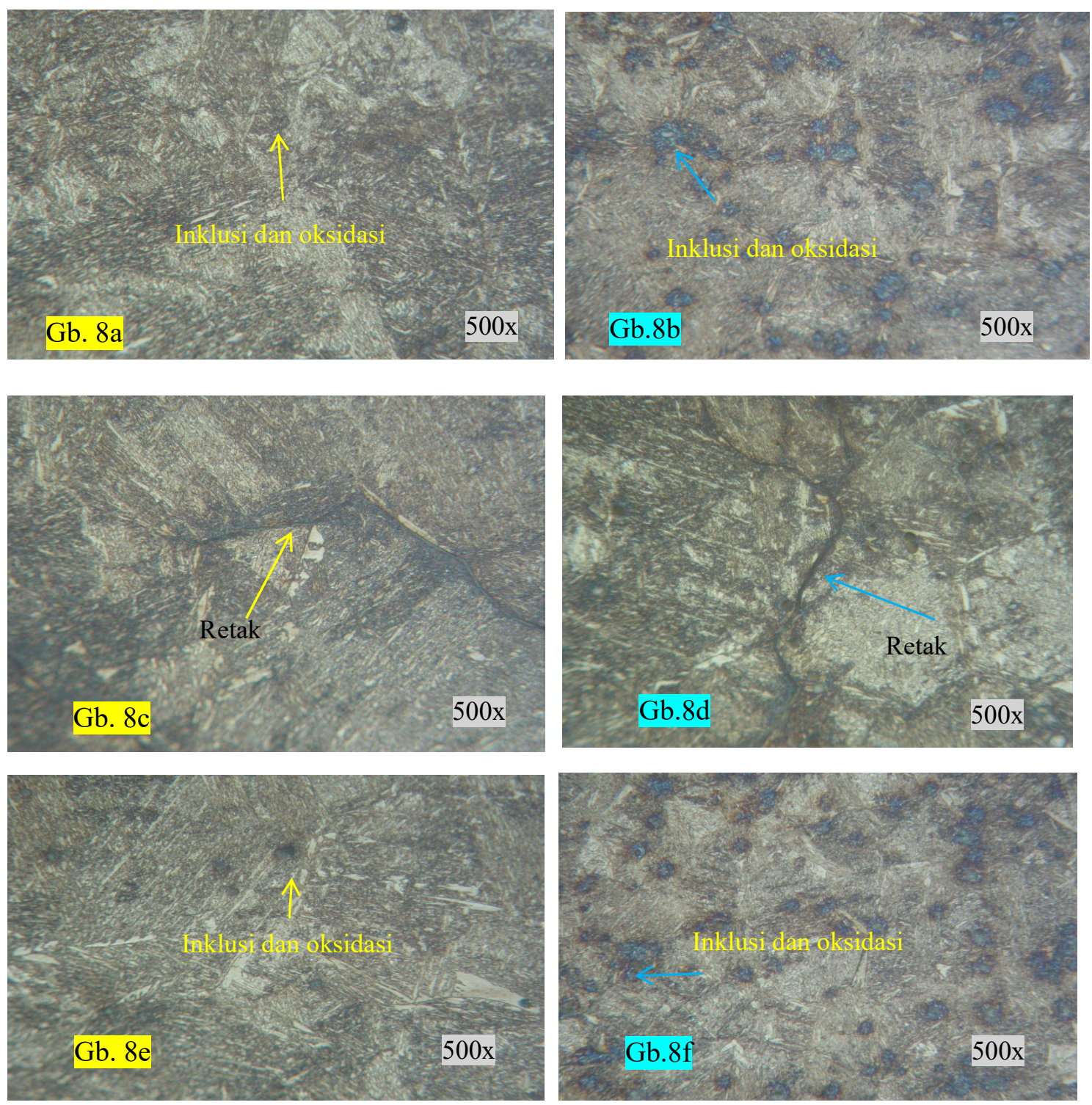

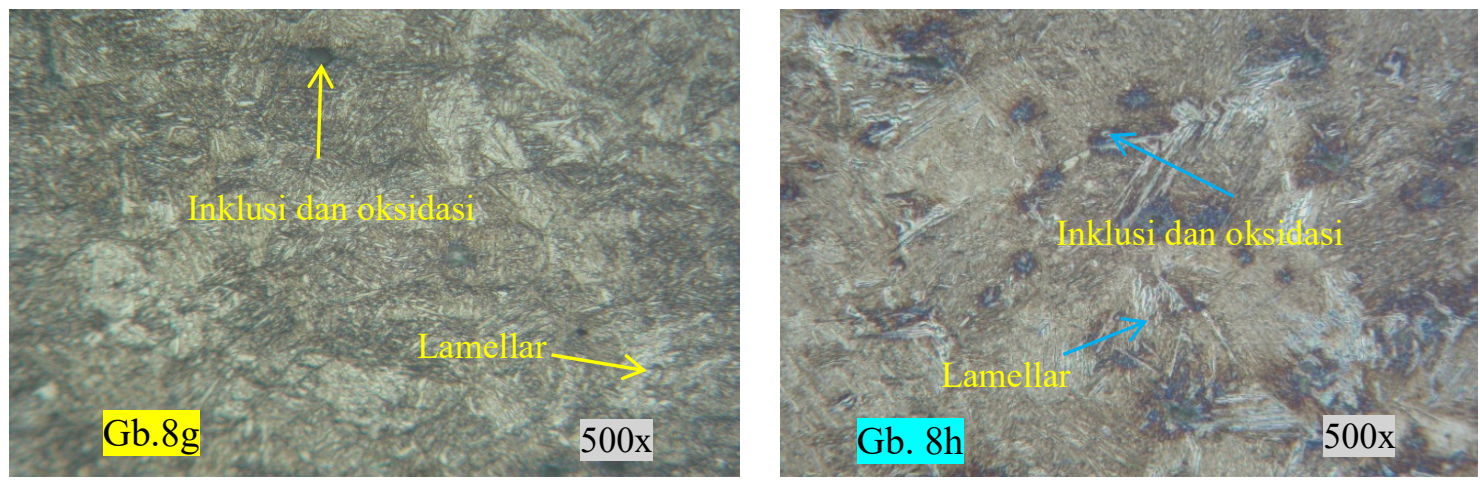

Gambar 8. Struktur Mikro Sampel Hardening Dari Pegas A dan B

Hasil heat treatment pegas daun mobil A dengan austenitisasi $805,7^{\circ} \mathrm{C}$, celup air, temper $206,9^{\circ} \mathrm{C}(\mathrm{Gambar}$ 8a) dan hasil heat treatment pegas daun mobil $\mathrm{B}$, dengan austenitisasi $810,7^{\circ} \mathrm{C}$, celup air, temper $236,1^{\circ} \mathrm{C}$ (Gambar 8b) menunjukkan struktur martensit dan austenit sisa. Inklusi kedua sampel tampak lebih jelas setelah heat treatment.

Sampel pegas A quench air (Gambar 8c), dan sampel pegas B (Gambar 8d) yang diquench dengan air menunjukkan keretakan berjenis intergranular. Etsa nital 2\%, perbesaran 500x.

Hasil heat treatment pegas daun A, austenitisasi $802,6^{\circ} \mathrm{C}$, celup oli, temper $218,6^{\circ} \mathrm{C}$ (Gambar $8 \mathrm{e}$ ) dan hasil heat treatment pegas $\mathrm{B}$, temperatur austenitisasi $817,8^{\circ} \mathrm{C}$, celup oli, temper $230,6^{\circ} \mathrm{C}$ (Gambar $8 \mathrm{f}$ ) sama-sama berstruktur mikro martensit dengan austenit sisa (warna putih) dan tidak muncul keretakan. Inklusi dan oksida pada kedua sampel tetap tampak jelas setelah heat treatment. Etsa nital 2\%, perbesaran 500x

Hasil heat treatment pegas daun mobil A, temperatur austenitisasi $803,4^{\circ} \mathrm{C}$, pendinginan getah pisang, temper $219,7^{\circ} \mathrm{C}$ (Gambar $8 \mathrm{~g}$ ) dan hasil heat treatment pegas daun mobil B pada temperatur austenitisasi $806,1^{\circ} \mathrm{C}$ dan pendinginan getah pisang, temper $230,1^{\circ} \mathrm{C}$ (Gambar $8 \mathrm{~h}$ ), keduanya berstruktur mikro martensit dan lamelar (campuran ferit-perlit-bainit). Inklusi kedua sampel tetap tampak. Tidak tampak keretakan pada kedua sampel. Perbesaran 500x.

Sampel pegas A dan B berstuktur matrik martensit temper, setelah hardening bertransformasi menjadi struktur martensit dengan austenite sisa. Retak jenis intergranular tampak pada sampel quench air. Sampel quench batang pisang berstruktur martensit dan lamelar yang merupakan campuran antara ferit, perlit. Dari ketiga media quenching, maka oli dianggap ideal untuk media quenching material pegas A dan B, karena struktur mikro yang muncul dominan martensit meskipun ada austenit sisa, namun tidak menimbulkan keretakan.
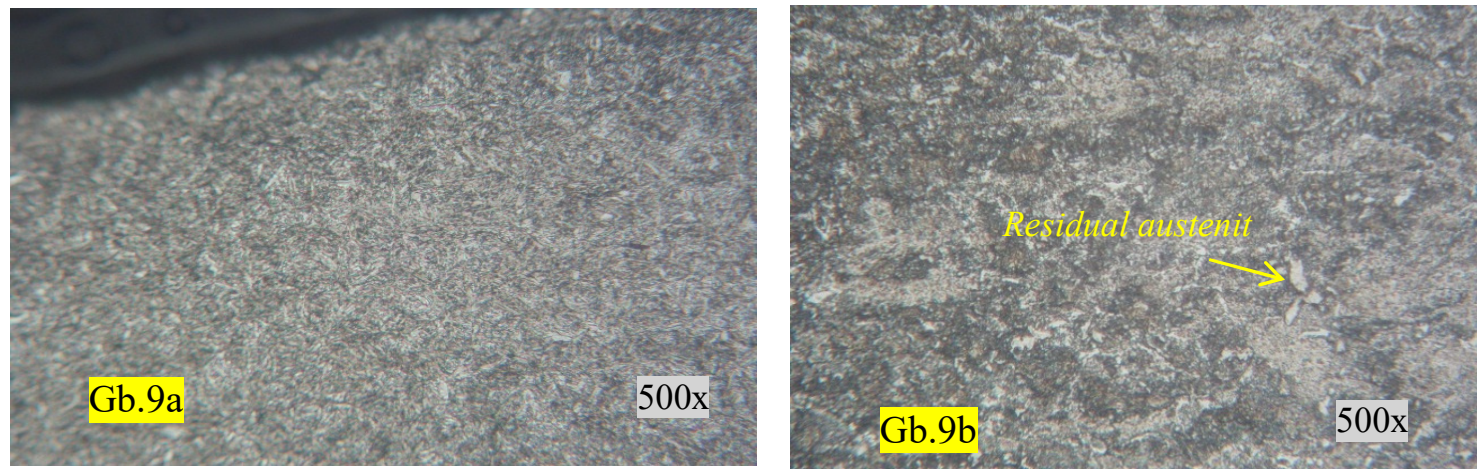

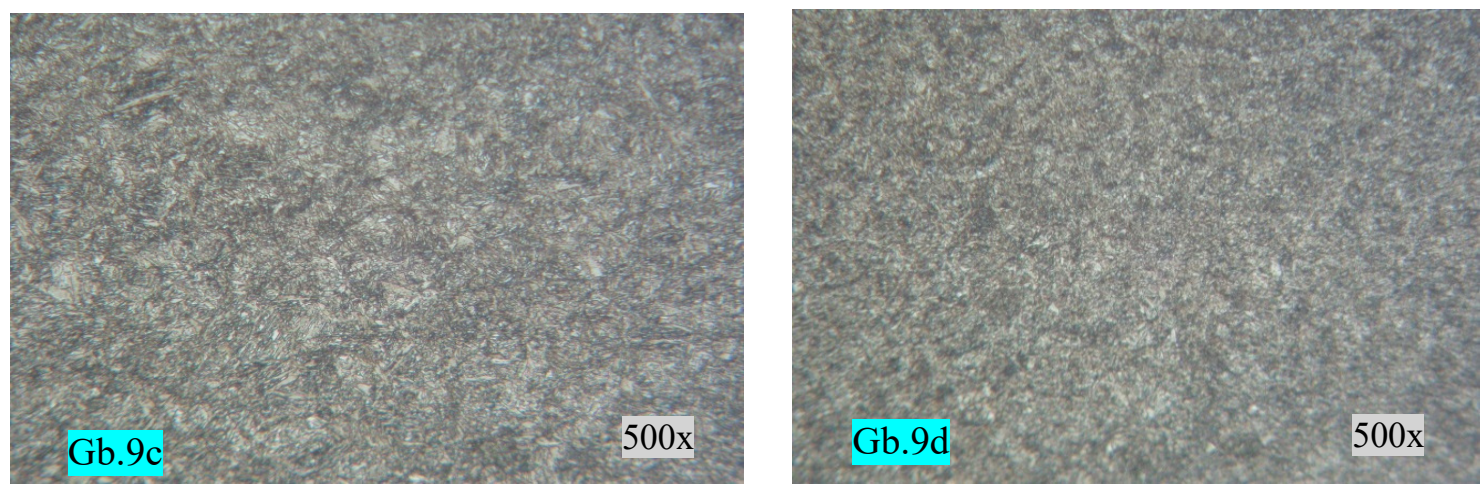

Gambar 9. Struktur Mikro Pisau Percobaan Berbahan Pegas A dan B

Pisau material pegas A yang disepuh bagian tajamnya dengan austenisasi $799,8^{\circ} \mathrm{C}$ celup oli, temper $338,3^{\circ} \mathrm{C}$ (Gambar 9a), berstruktur mikro martensit dengan butir karbida krom (speroidized carbide) menyebar rata. Pada daerah tebal yang tidak ditimbun bara api (Gambar 9b), struktur mikro berupa martensit halus dan sisa austenit dibatas butir. Tidak ada keretakan pada pisau dan inklusi tidak tampak jelas lagi setelah penempaan. Etsa nital $2 \%$, perbesaran $500 x$.

Pisau material pegas B yang disepuh menyeluruh dengan temperature $792,5^{\circ} \mathrm{C}$, quenching oli, temper $353,2^{\circ} \mathrm{C}$ berstruktur mikro martensit dengan butir karbida krom (speroidized carbide) menyebar rata. Pada daerah tajam (Gambar 9c) maupun daerah tebal pisau (Gambar 9d) berstruktur mikro berupa martensit halus dan sisa austenit dibatas butir. Tidak tampak inklusi dan keretakan pada pisau B pada sisi tajam maupun sisi tebalnya. Etsa nital $2 \%$.

Struktur mikro pisau percobaan berbahan pegas A dan B quench oli mendekati struktur mikro pisau impor X, yaitu martensit dengan karbida halus yang menyebar rata. Inklusi yang tampak pada raw maerial maupun setelah heat treatment tidak tampak setelah penempaan. Hal ini dikarenakan penempaan memberikan efek padat pada material.

\section{Hasil Pengujian Kekerasan Dan Analisis}

Pisau impor X yang diuji pada bagian dalamnya dengan HV (Gambar 10a) dan diukur pada sisi luar/sampingya dengan HRC (Gambar 10b).
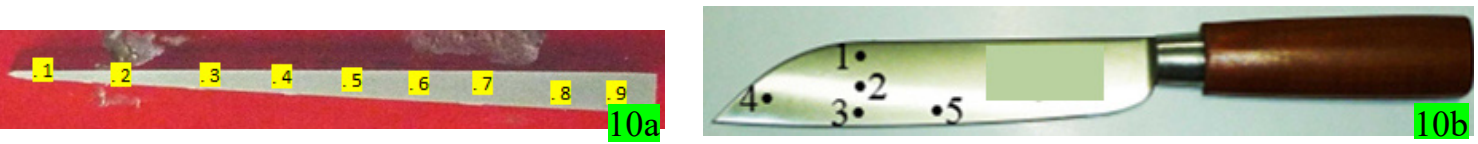

Gambar 10. Daerah pengujian kekerasan HV dan HRC pada pisau impor X

Tabel 5. Hasil uji kekerasan pisau $X$

\begin{tabular}{|c|c|c|c|c|c|c|c|c|c|c|c|}
\hline \multirow{3}{*}{$\begin{array}{c}\text { Pisau } \\
\text { Impor X }\end{array}$} & Titik & 1 & 2 & 3 & 4 & 5 & 6 & 7 & 8 & 9 & Ave- \\
\hline & HV & 612 & 608 & 612 & 612 & 612 & 612 & 642 & 602 & 622 & 615 \\
\hline & HRC & 55,5 & 57,2 & 62 & 56,5 & 57 & - & - & - & - & 57,6 \\
\hline
\end{tabular}

Berikut adalah titik pengukuran kekerasan sampel pada bagian dalam (Gambar 10a) dengan HV dan hasilnya ditampilkan dalam Tabel 6 Sementara hasil pengukuran bagian luar sampel (Gambar 11b) dengan HRC hasilnya ditunjukkan dalam Tabel 7.
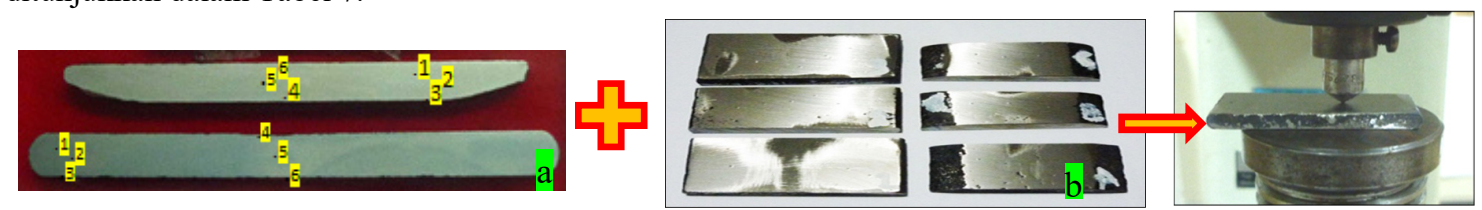

Gambar 11. Daerah spacimen yang diuji dengan (a) HV dan (b)HRC 
Tabel 6. Nilai kekerasan bagian dalam sampel hardening pegas A dan B dengan HV

\begin{tabular}{lccccccc}
\hline \multirow{2}{*}{ No } & \multirow{2}{*}{ Sampel } & \multicolumn{3}{c}{ Temperatur dalam ${ }^{\mathbf{C}}$} & \multicolumn{3}{c}{ Kekerasan Dalam Vickers (HV) } \\
\cline { 2 - 7 } & & Austenisasi & Temper & Titik 1 & Titik 2 & Titik 3 & Ave- \\
\hline 1. & Raw Material A & - & - & 412 & 418 & 423 & 419 \\
2. & A Quench Air & 805,7 & 206,9 & 781 & 781 & 753 & 771 \\
3. & A Quench Oli & 802,6 & 218,6 & 767 & 767 & 712 & 748 \\
4. & A Quench Batang Pisang & 803,4 & 219,7 & 725 & 725 & 725 & 725 \\
5. & Raw material B & - & - & 460 & 460 & 460 & 460 \\
6. & B Quench Air & 810,7 & 236,1 & 767 & 753 & 753 & 757 \\
7. & B Quench Oli & 817,8 & 230,6 & 753 & 753 & 767 & 747 \\
8. & B Quench Batang Pisang & 806,1 & 230,1 & 739 & 739 & 725 & 734 \\
\hline
\end{tabular}

Semua sampel pegas A hasil heat treatment apabila diukur kekerasannya pada bagian dalam dengan kekerasan awal $419 \mathrm{HV}$ meningkat rata-rata lebih dari $700 \mathrm{HV}$. Sementara pegas B dari semula $460 \mathrm{HV}$ juga meningkat menjadi lebih dari $700 \mathrm{HV}$.

Tabel 7. Nilai kekerasan bidang luar sampel hardening pegas A dan B dengan HRC

\begin{tabular}{cccccccc}
\hline \multirow{2}{*}{ No } & \multirow{2}{*}{ Sampel } & \multicolumn{3}{c}{ Temperatur dalam $^{\mathbf{O} C}$} & \multicolumn{4}{c}{ Kekerasan Dalam (HRC) } \\
\cline { 2 - 7 } & & Austenisasi & Temper & Titik 1 & Titik 2 & Titik 3 & $\leq$ HRC \\
\hline 1. & A1 Quench Air & 805,7 & 206,9 & 60 & 62,7 & 62,5 & 60,5 \\
2. & A2 Quench Oli & 802,6 & 218,6 & 57 & 62 & 59,2 & 59,4 \\
3. & A3 Quench Batang Pisang & 803,4 & 219,7 & 58 & 59,2 & 62 & 59,7 \\
4. & B1 Quench Air & 810,7 & 236,1 & 62 & 61 & 62 & 61,6 \\
5. & B2Quench Oli & 817,8 & 230,6 & 62 & 61,5 & 62 & 61,8 \\
6. & B3 Quench Batang Pisang & 806,1 & 230,1 & 59,8 & 59,5 & 61,5 & 60,2 \\
\hline
\end{tabular}

Sisi luar sampel pegas A yang semula memiliki kekerasan 42HRC meningkat menjadi 59-60HRC, dan pegas B yang semula 46 HRC meningkat menjadi 60-61,8HRC. Kekerasan yang terbentuk dari hasil heat treatment pada bagian dalam dan luar sampel kedua pegas cukup tinggi, hal ini akan sangat beresiko terjadi keretakan pada bilah pisau, mengingat bilah yang telah ditempa memiliki dimensi yang tipis $( \pm 1,9 \mathrm{~mm})$. Maka dalam pelaksanaan penyepuhan pisau, kekerasan pisau perlu diturunkan sedikit dengan laku temper agar terhindar dari resiko keretakan bilah yang sudah sampai pada tahap pengerjaan akhir.

Pisau hasil percobaan yang diuji kekerasannya pada bagian dalam dengan HV (Gambar 12a) dan bagian luar dengan HRC (Gambar 12b) menunjukkan hasil seperti pada Tabel 8.
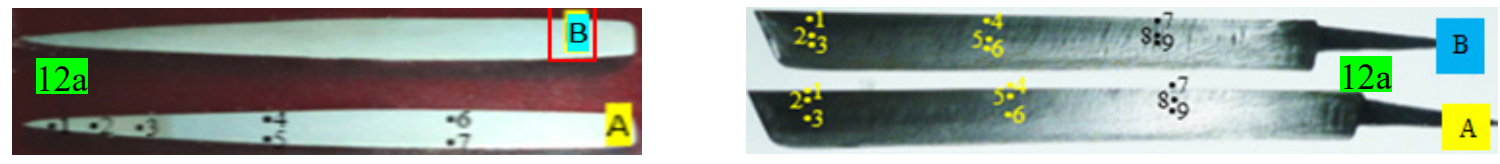

Gambar 12. Daerah uji kekerasan pisau percobaan 
36 | Abdul Choliq, dkk., Optimalisasi Heat Treatment pada Proses Daur Ulang Pegas ....,

Tabel 8. Nilai kekerasan bagian dalam pisau percobaan dalam (HV)

\begin{tabular}{llccccccccc}
\hline \multirow{2}{*}{ No } & \multirow{2}{*}{ Pisau } & \multicolumn{2}{c}{ Temperatur dalam $^{\mathbf{C}} \mathbf{C}$} & \multicolumn{1}{c}{ Titik } \\
\cline { 2 - 12 } & Austenisasi & Temper & $\mathbf{1}$ & $\mathbf{2}$ & $\mathbf{3}$ & $\mathbf{4}$ & $\mathbf{5}$ & $\mathbf{6}$ & $\mathbf{7}$ \\
\hline 1. & Pisau A, & 799,8 & 353,2 & 732 & 753 & 725 & 313 & 313 & 306 & 309 \\
\hline 2. & Pisau B, & 792,5 & 353,2 & 612 & 622 & 622 & 622 & 642 & 632 & 643 \\
\hline
\end{tabular}

Level kekerasan bagian dalam pisau percobaan A, pada mata pisau/daerah yang dikeraskan, level kekerasan mencapai 725-753HV (angka yang diblok). Sedangkan daerah yang tidak dikeraskan justru turun antara 309313HV (angka tanpa blok). Hal ini terjadi karena pada saat heat treatment, daerah yang ditimbun bara arang untuk mencapai temperatur austenisasi pada pisau A hanya pada daerah mata pisau saja. Sedangkan daerah tumpul tidak mencapai temperatur austenisasi karena tidak tertimbun bara arang. Maka setelah diquench, daerah yang mengalami efek pengerasan hanya daerah tajam saja, sedangkan daerah tupul justru turun karena mengalami pemanasan berulang saat penempaan tanpa adanya perlakuan panas untuk menaikkan kekerasannya. Sementara itu pisau B yang dikeraskan pada seluruh bagian dengan cara menimbun seluruh bagian dengan bara arang saat austenisasi mencapai kekerasan antara 622-643 HV. Dengan demikian tingkat kekerasan pisau A maupun B pada daerah yang sengaja dikeraskan mencapai level kekerasan yang mendekati level kekerasan pisau impor X, yaitu $615 \mathrm{HV}$.

Tabel 9. Nilai kekerasan bidang luar pisau percobaan dalam HRC

\begin{tabular}{llccccccccc}
\hline \multirow{2}{*}{ No } & \multirow{2}{*}{ Pisau Percobaan } & \multicolumn{8}{c}{ Nilai Kekerasan dalam HRC pada Beberapa Titik } \\
\cline { 3 - 11 } & & 1 & 2 & 3 & 4 & 5 & 6 & 7 & 8 & 9 \\
\hline 1. & Pisau A & 34 & 38 & 60 & 33 & 39 & 53 & 33 & 38 & 49 \\
\hline 2 & Pisau B & 57 & 56 & 55 & 58 & 58 & 57 & 53 & 58 & 52 \\
\hline
\end{tabular}

Dari hasil penempaan dan hardening pisau, tampak bahwa level kekerasan sisi luar pisau percobaan A pada mata pisau atau daerah yang dikeraskan dengan ditimbun bara arang saat austenisasi mencapai 49-60HRC (angka yang diblok), sedangkan daerah yang tidak ditimbun bara arang saat austenisasi justru turun antara 33-39 HRC. Sementara itu, pisau B yang dikeraskan secara keseluruhan dengan menimbun seluruh bagian pisau dengan bara arang saat austenisasi mencapai kekerasan antara 52-58 HRC. Dengan demikian kekerasan pisau pada daerah yang dikeraskan mampu mendekati level kekerasan pisau impor X, yaitu 57,6 HRC. Secara sederhana, perubahan level kekerasan raw material pegas dan perubahan level kekerasan setelah dibuat pisau melalui penempaan dan heat treatment serta perbandingan dengan pisau impor merk X dapat ditampilkan dalam grafik berikut.

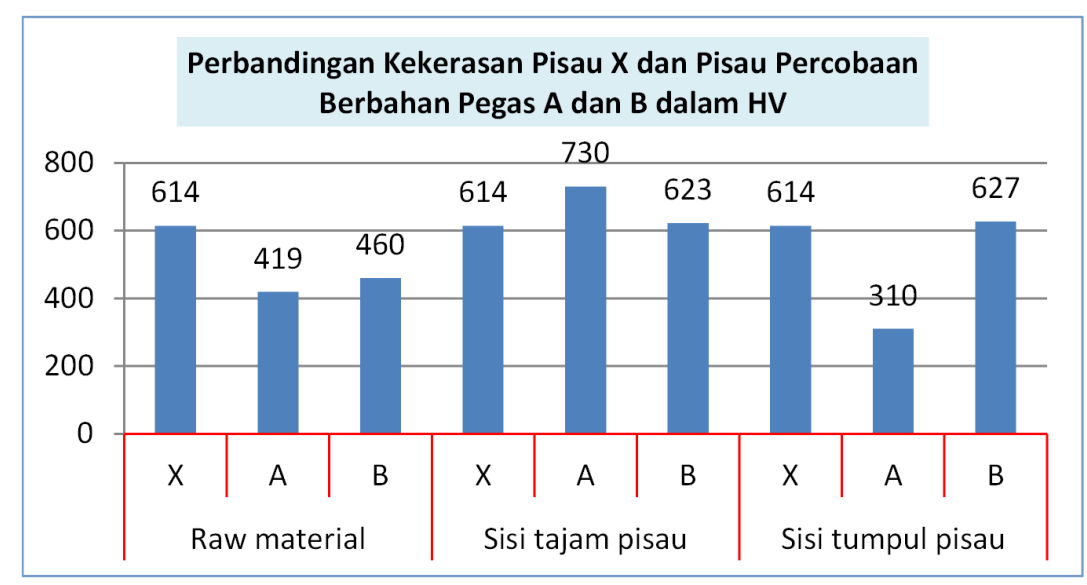

Gambar 13. Grafik perubahan nilai kekerasan pisau A dan B 


\section{KESIMPULAN}

Pegas daun mobil A dan B serta bilah pisau X berjenis baja karbon medium dengan paduan $<8 \%$ dan sesuai untuk cutting tool ${ }^{[3]}$ karena memiliki mampu tempa dan mampu keras yang baik, hal ini menguatkan alasan pemilihan kedua material untuk dijadikan material alternatif bilah pisau. Pegas A dan B yang semula berstruktur mikro matrik martensit temper, dengan kekerasan $419 \mathrm{HV}$ dan $460 \mathrm{HV}$ dapat dibentuk menjadi bilah pisau sembelih hewan dengan level kekerasan $730 \mathrm{HV}$ dan $627 \mathrm{HV}$, dan struktur mikro yang lebih padat berupa martensit temper dengan karbida krom (speroidized carbide). Karakter tersebut mendekati kekerasan pisau $\mathrm{X}$ yang berstruktur mikro martensit temper dengan karbida halus, level kekerasan 614HV. Stuktur dan kekerasan tersebut diperoleh melalui proses tempa bebas dengan pemanas tungku tradisional, bahan bakar arang kayu. Penyepuhan dengan temperatur austenisasi $\pm 800^{\circ} \mathrm{C}$, holding time 15 detik, quench 15 liter oli mesin bekas bertemperatur $30^{\circ} \mathrm{C}$ dan ditemper pada temperatur $350^{\circ} \mathrm{C}$, holding time 15 detik dan pendinginan udara. Penempaan secara berulang memberikan efek padat pada pisau, sehingga inklusi yang ada pada raw material tidak tampak pada pisau percobaan setelah penempaan.

\section{DAFTAR PUSTAKA}

[1] Badan Pusat Statistik (2018). Jumlah Ternak Dipotong di RPH dan Luar RPH Yang Dilaporkan (Report) BPS Statistic Indonesia. https://www.bps.go.id

[2] Balkhaya, Suwarno (2017), Effect of Raw Materials and Hardening Process on Hardness of Manually Forged Knife,[Journal] AIP Conference Proceedings 1855, 030010 (2017); https://doi.org/10.1063/1.4985480

[3] Balkhaya1*, M P Anhar, Suwarno, M S M Sani (2019), Investigation of knife quality by using forging and flame hardening methods, IOP Conf. Series: Materials Science and Engineering 506 (2019) 012004

[4] Bringas, John E.(2002). Handbook of Comparative Word Steel Standards ASTM DS 67 B [Book] ed. Bringas John E. Danver, USA ; ASTM International, 2002. 3 : pp. 418, 420,433,302,367,435.

[5] Boye David Step by Step Knife Making (2018). Step by step knife making you can do it. [Online] http://www.knifehelp.net/media/docs/Boye

[6] Direktori Perusahaan Pertanian rumah Potong Hewan (RPH) dan Tempat Pemotongan Hewan (TPH) (2018). Jumlah RPH dan TPH di Indonesia 2018, Katalog 1305016 [Report] BPS Statistic Indonesia. https://www.bps.go.id

[7] Direktorat Jendral Peternakan (2018). Kementrian Pertanian Jamin Ketersediaan dan Kesehatan Ternak Untuk Hari Raya Idul Adha. http://ditjennak.pertanian.go.id

[8] Fitri Ediman Ginting, Pulung Karo-karo (2013). Komposisi Kimia, Struktur Mikro, Holding Time dan Sifat [Journal] Universitas Lampung. Jurnal Teori dan Aplikasi Fisika. Vol. 01, No. 01.

[9] Gruber, Ing. Alois Schonmetz (2013). Pengetahuan Bahan dalam Pengerjaan Logam [Book]. Angkasa Bandung.

[10] Seco/Warwick, (2011) Heat Treating Data Book - Tenth Edition E-Book, Meadvill USA

[11] Ing. Alois Schonmetz Ing. Adolf Frischherrz, Ing. Rudolf Domayer, Ing. Peter Sinnl (2013). Pengerjaan Logam dengan Perkakas Tangan dan Mesin Sederhana [Book] trans. Hardjapamekas Diplom-Ing. Eddy D. Angkasa, Bandung.

[12] Prihanto Trihutomo (2015). Analisa Kekerasan Pada Pisau Berbahan Baja Karbon Menengah Hasil Proses Hardening Dengan Media Pendigin Berbeda [Journal] Jurnal Teknik Mesin,Tahun 23 No. 1. - [s.1.] Universitas Negeri Malang.

[13] Prayitno, Dody (2010). Teknologi Rekayasa Material [Book]. Universitas Trisakti, Jakarta - pp. 85,86,87,88,89.

[14] Roymons Jimmy Dimu, Denny Widhiyanuriyawan (2014). Optimasi Hardening Baja Karbon Sedang dengan Fluida Getah Pohon Pisang Menggunakan Metode Taguchi. Jurnal Rekayasa Mesin Vol.5 No.2 Fakultas Teknik Universitas Brawijaya Malang. ISSN 0216-468X.

[15] SCTV Liputan 6 (2005). Golok Cibatu terkenal hingga penjuru dunia [Report]. - Jakarta Indonesia. https://www.liputan6.com/news/read/114385/

[16] Tata Surdia, Shinroku Saito (2013). Pengetahuan Bahan Teknik [Book]. - Jakarta timur : PT. Balai Pustaka - p. 94 